\title{
Can Design Thinking Enhance Experiential Heritage Tourism in Pakistan?
}

Page 01

Received 29 June 2019 Revised 12 Sep 2019 Accepted 30 Oct 2019

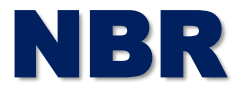

NUST Business Review Vol. 01, No. 01 10, 2019 pp. 01-11 (c) NUST Business School

\author{
Joanna Seraphim \\ Head of Incubation Centre, Amity University, Dubai, UAE \\ Farooq Haq \\ Faculty of Management, Canadian University of Dubai, UAE
}

\section{Key Points:}

- Design Thinking has been applied to expose the benefits for Pakistan in terms of heritage tourism.

- There is a need to valorize heritage sites in Pakistan in order to protect them, and develop the local economy through heritage tourism, in turn, creating a positive image of the country, (Haq E Medhekar, 2019).

- In adding experience in heritage tourism, Pakistan could innovate the heritage tourism sector and attract more tourists.

Keywords: Pakistan, experiential heritage tourism, Design Thinking, authenticity, memorability, satisfaction, engagement.

Paper Type: Conceptual Paper 


\subsection{Introduction}

The present Pakistani Government has shifted the focus of its economic and

NBR

1,1

Page 02

Table 1.

The 5 steps of

design thinking,

adopted from the

d.school at

Stanford

University

(d.school, 2010). financial capabilities towards tourism (Haq \& Medhekar, 2019). Pakistani tourism has been targeting natural, economic, and religious tourists, where heritage tourism has been overlooked for managerial, economic and political reasons (Haq \& Medhekar, 2019). This paper highlights the trend that businesses involved in heritage tourism are recognizing the potential of experiential tourism as the innovation required for success. For example, many museums are developing experiences besides their traditional exhibition. Hence, providers of heritage services, focusing on sustaining the heritage value of Pakistan, are designing more activities and events centered on visitors and their experiences. This research stresses upon the importance of heritage tourism for Pakistan that is considered less significant by tourism organizers. Although, the new government appreciates the crucial role of tourism in building a nation, yet the benefits of heritage tourism are officially not recognized. The financial cost of general hedonistic tourism based on tangible assets has also prompted the search for commercially manageable and thoughtful tourism.

The search for thoughtful tourism for travelers and viable for business operators leads this study towards heritage tourism. Among various types of heritage tourism, experiential is more controllable and sustainable compared to behavioral and leisure heritage tourism (Balmer \& Chen, 2016). The history of tourism in Pakistan showcases the unrealistic goal of establishing the image of a modern and fun-based tourism hub (Baloch, 2007). Consequently, this has led to neglect or even annihilation of such historical sites. Among many, an outstanding example is the destruction of various heritage sites in Lahore while building the Orange Train and Metro Bus Services. This study advocates to follow the global trend of a switch in favor of history and heritage-based tourism to improve the tourism image (Papadimitriou, Kaplanidou \& Apostolopoulou, 2018).

This research applies the design thinking process to develop new experiences based on better information, booking services, and packaging for heritage tourists in Pakistan. Design thinking is defined as "a process for creative solving" (IDEOU, 2018). It is a human-centered process that includes five steps: empathy, defining, ideation, prototyping, and testing (Liedtka, Salzman \& Azer, 2017). One of the authors of this paper has attended design thinking workshops at the D.School in Stanford University, and has suggested its application for this research.

\begin{tabular}{cl}
\hline Design & Thinking Steps \\
\hline 1. & Empathize \\
2. & Define \\
3. & Ideate \\
4. & Prototype \\
5. & Test \\
\hline
\end{tabular}


NBR

1,1

Page 03

Design Thinking has several approaches; the d.school approach based on the five steps is a structured approach. For example, Kelley and Kelley (2013) reported that Stanford University students were sent to India and Nepal to try to find a way to produce incubators for a cheaper cost for areas who could not afford it. After interviewing mothers and visiting hospitals (empathy step), the students realized that the problem was not the incubators' price. The real issue was that mothers in rural area could not reach city hospitals with incubators (defining step). They brainstormed many solutions, and finally prototyped a sleeping bag for premature babies. After testing it in rural areas and refining it, "Embrace Infant Warmer" was born. This product is a sleeping bag that helps low birth weight babies to keep their body temperature. (Kelley \& Kelley, 2013).

The first four steps of design thinking are aligned with various stages of the research process embraced in this study. The empathy indicates the purpose and benefits of the study. The defining stage demonstrates considerations set to facilitate the research process. The ideation explains the data analysis and data triangulation. The prototyping presents the concluding concepts for this study. The fifth step of testing includes primary research, which is beyond the scope of this paper and will be included in a future empirical study.

The purpose of this paper is to study if design thinking could be applied to enhance the experiential heritage tourism in Pakistan. This purpose will be fulfilled by following two research goals: (i) underline the current position and various elements building experience-based heritage tourism in Pakistan constructed on secondary data from public and private resources, and (ii) demonstrate how design thinking can be applied to enhance heritage tourism experiences in Pakistan.

$\mathrm{n}$ a culture at a given period and between cultures through time. International Council on Monuments and Sites (ICOMOS) defined "heritage" as a broad concept that includes tangible assets such as natural and cultural environment, encompassing landscape, historic places, and build environment as well as intangible assets such as the collection of past and continuing cultural practices, knowledge, and living experiences (ICOMOS, 2002). Heritage tourism can be divided into two sectors: natural heritage and cultural heritage (Seraphim \& Haq, 2019). The natural heritage includes natural spectacles, such as jungles, lakes, mountains and coastlines, while cultural heritage encompasses the history made by people and its various expositions (Chhabra, Healy, \& Sills, 2003).

\subsection{Literature}

Tourism is accepted as the fastest growing service sectors of today's global economy and one of the highest employment generators that injects with over $10 \%$ to global GDP. International tourist arrivals reached a total of 1.4 billion in 2018, which is around $6 \%$ more than the previous year and hence breaks all records (UNWTO, 2019). The present Pakistani Government has shown keen interest in developing national tourism, which Haq and Medhekar (2019) identified as the missing ingredient in its success. Tourism in the world has globally shown continuous growth in arrivals for eight straight years, the growth in 2017 was the 
NBR

1,1

Page 04

highest since 2010, which experienced a rise in arrivals of $8 \%$ and 9\% (UNWTO, 2018). Tourism in Pakistan has also grown, despite its low numbers. In 2015, only 536,000 international tourists visited Pakistan, whereas in 2016, they were 965,000. The following year, 1.6 million visitors enjoyed Pakistan touristic sites, and in 2018, the number of tourists reached 1.9 million persons (The Express Tribune, 2019).

\subsection{Heritage Tourism}

Heritage tourism has been observed to be a pre-historic form of travel, recently accepted as a type of tourism associated with culture, religion, historical customs and social traditions (Balmer \& Chen, 2016; Chhabra, Healy, \& Sills, 2003). Balmer and Chen (2016) concluded that heritage can be translated differently within a culture at a given period and between cultures through time. International Council on Monuments and Sites (ICOMOS) defined "heritage" as a broad concept that includes tangible assets such as natural and cultural environment, encompassing landscape, historic places, and build environment as well as intangible assets such as the collection of past and continuing cultural practices, knowledge, and living experiences (ICOMOS, 2002). Heritage tourism can be divided into two sectors: natural heritage and cultural heritage (Seraphim \& Haq, 2019). The natural heritage includes natural spectacles, such as jungles, lakes, mountains and coastlines, while cultural heritage encompasses the history made by people and its various expositions (Chhabra, Healy, \& Sills, 2003).

In Pakistan, six tangible heritage sites have been identified (UNESCO, 2019): Archaeological Ruins at Moenjodaro (1980), Buddhist Ruins of Takht-i-Bahi and Neighboring City Remains at Sahr-i-Bahlol (1980), Fort and Shalamar Gardens in Lahore (1981), Historical Monuments at Makli, Thatta (1981), Rohtas Fort (1997) and Taxila (1980). A list of heritage sites that are waiting to be applied for recognition from World Heritage Centre includes: Badshahi Mosque, Lahore (1993), Wazir Khan's Mosque, Lahore (1993), and Tombs of Jahangir, Asif Khan and Akbari Sarai, Lahore (1993).

\subsection{Experiential Heritage Tourism}

The tourism experience is simply an outcome of physical, emotional, spiritual, and/or intellectual influences, which is individually perceived by tourists since they start planning their trip, while enoying it, and until they are back home (Andrades \& Dimanche, 2014; Otto \& Ritchie, 1996). The literature on heritage tourism as an experience for tourists is almost nonexistent in Pakistan, motivating this study to highlight various tourism products and services in Pakistan that come under the umbrella of heritage tourism (Haq \& Medhekar, 2019). The government and private tourism operators of Pakistan need to recognize the commercial and social benefits of heritage tourism (Haq \& Medhekar, 2019; Baloch, 2007). Essential elements that emerged from the triangulation of secondary data sources (from the literature) to be discussed and analyzed as findings of this research are detailed below.

\subsection{Involvement}

Involvement of a tourist in the destination and activities is the focal point of 
NBR

1,1

Page 05

experiential tourism (Meyer \& Schwager, 2007; Otto \& Ritchie, 1996). Meyer \& Schwager (2007, p.2) described the customer experience as "the internal and subjective reactions and feelings experienced by consumers when they have any direct or indirect contact with the company". Tourist involvement enhances the experience, as the tourist becomes a part of the tourism process through activities such as scuba diving, rafting, and bungee jumping (Seraphim \& Haq, 2019). In this study on experiential heritage tourism, the direct or indirect contact with the tourism products and services will be measured as customer involvement

\subsection{Memorability}

In order to achieve customer satisfaction and destination loyalty, tourist experience must contain the sense of memorability (Andrades \& Dimanche, 2014; Cary, 2004). As discussed, involvement of the tourist enhances the experience; similarly, the ever staying and meaningful effect of the journey is reflected by its memorability. Cary $(2004$, p. 63) further explains that the memorability of a tourist experience depends upon unplanned, incidental, and casual moments for tourists that "simultaneously produces and erases the tourist as a subject". The memorability of a tourist includes the unexpected help from tourism providers, for example free drinks or sweets, a lift in personal car due to unavailability of taxis, or a free copy of the city guide (Seraphim \& Haq, 2019). Tourism operators realize that higher the memorability of any tourism experience, in turn, higher will be the loyalty, travel frequency, and feedback by the travelers (Andrades \& Dimanche, 2014).

\subsection{Satisfaction}

The satisfaction of a tourist can be described as the most expected result of tourism experiences (Andrades \& Dimanche, 2014). Furthermore, Otto \& Ritchie (1996) claimed from empirical research that a tourist is satisfied from the travel experience if there is a clear mapping between the need and performance. A tourist will be satisfied if he/she achieve what he/she expected before the trip. For example, for heritage tourists it could be a thorough knowledge of the history of the place (Seraphim \& Haq, 2019).

Similarly, Haq and Jackson (2009) explained that dissatisfaction is the outcome of a wide variance between expectation and experience of a tourist. The tourism experience is built on two features: existential reality and structural reality (Otto \& Ritchie, 1996; Hamilton-Smith, 1987). Hamilton-Smith (1987, p.334) further explained that the existential reality indicates "high levels of satisfaction, freedom, involvement and (intrinsic) reward", while structural reality involves "the extent to which the activity is task oriented and wherein completion is externally reinforced". The experiential heritage tourism is more associated with existential reality since a satisfied heritage tourist seeks more freedom and self-fulfillment rather than a highly organized tourism outcome (Haq \& Medhekar, 2019).

\subsection{Authenticity}

The element of authenticity in tourism experiences has primarily being analyzed by Redfoot (1984). Redfoot (1984, p.291) defined authenticity as: "the tourist has become the symbol of a peculiarly modern type of inauthenticity." Andrades and 
NBR

1,1

Page 06

Dimanche (2014) further explained that authenticity in a tourism experience is based on reality experiences of tourists and depends upon different perceptions of tourists contributing towards their own form of inauthenticity. For example, a tourist studying Mogul Heritage in India and Pakistan will prefer to visit an authentic Mosque or Mausoleum built by a Mogul King rather than a modern-day replica (Haq \& Medhekar, 2019). Chhabra et al. (2003, p. 702) argued about authenticity in tourism experiences as, "much of today's heritage tourism product depends on the staging or re-creation of ethnic or cultural traditions".

\subsection{Innovation in Tourism}

Weiermair (2006) claims that tourists seek experience rather than destination, hence the experience could be offered by innovatively presenting the tourism product as an experience. A destination acts as a stage where various tourism agents become actors and continuous learning for customers can transform the tourism experience into an innovation (Haq and Medhekar, 2016; Hjalager, 2010). Therefore, in modern markets, the heritage tourism product, or rather an experience, can be presented as an innovation in tourism (Haq \& Medhekar, 2017; Seraphim and Haq, 2019).

\subsection{Methodology}

Since there is a scarcity of literature on experiential heritage tourism and related topics in most countries including Pakistan, this paper attempts to fill this gap in literature by presenting triangulated secondary data. Denzin (2012) presented triangulation as a type of analysis where qualitative data collected from various primary and secondary sources is screened to reach research conclusions. In this study, secondary data collected from public and private sources such as publications, magazines, research outcomes, books, online essays, and newspapers was triangulated to extract information regarding design thinking related to heritage tourism in Pakistan. The central research question for this conceptual study is: "can design thinking be applied to enhance the experiential heritage tourism in Pakistan"? This research will adopt an exploratory research methodology based on secondary data crystallized to present and establish credible theory that could be used for further empirical research, qualitative and quantitative.

\subsection{Findings and Discussion}

In this research, the secondary data was collected and analyzed separately by both authors to reach credible findings. Both researchers extracted information from data analysis related to the research purpose, then the emerging themes were triangulated to decide upon the final findings. The first step of the design thinking process is empathy, which is mapped with the purpose and benefits of this study. The purpose has been mentioned, benefits can be presented in three aspects: commercial, social and the country's image, as suggested by Papadimitriou et al. (2018). The commercial benefit of any form of tourism does not need any elaboration. The social aspect is critical as it will influence the people, government and society. For the empathy steps, secondary data were analyzed to understand the needs of the country. 
NBR

1,1

Page 07

Pakistanis are generally unaware about the heritage treasures they possess (Haq \& Medhekar, 2019; Seraphim \& Haq, 2019). For example, it was observed by one of the authors that several forts and castles in Pakistan, there for many centuries, are facing wilderness and anonymity since the locals are not aware of its value. The propagation of heritage sites will educate the locals also about the value and history of the place. Once the locals will value their heritage then they will pass it on to visiting foreigners (Haq \& Medhekar, 2017).

Defining is the second step of the design thinking process, which indicates the conditions set to facilitate the research process to reach useful findings. In this step, it was concluded that Pakistan needs to improve experiential heritage tourism. The insights revealed were that experiential heritage tourism was needed in order to protect heritage sites, to teach the local population about the importance and the significance of these sites, but also to develop the local economy and to present a positive image of the country. The study of the secondary data was mapped with the aim to enhance experience of heritage tourism in Pakistan; hence every material studied or reviewed was ticked in or crossed out as per the need of the study.

The next steps of the design thinking process are ideation and prototyping that illustrate the data analysis. For this research, ideation and prototyping were mapped with the secondary data analyzed to build the theory for experiential heritage tourism in Pakistan. The key elements supporting the experiential heritage tourism have been explained in the literature review and will be discussed with respect to tourism in Pakistan.

It has been clarified that involvement for tourists is the corner stone for any experiential tourism. In Pakistan, the involvement has never been understood by tourism operators; let alone applying it (Haq \& Medhekar, 2019). The tourism operators need to know that all tourists in general, heritage tourists in specific, travel to engage with the people, places, monuments, nature, food, and even the residence. Tourists taking selfies with all these items are a clear example of involvement. Based on examples from the literature, activities need to be planned and presented to tourists for their involvement.

Memorability also signifies experiential heritage tourism, which seems to be ignored by tourism operators in Pakistan (Haq \& Medhekar, 2019). It has been anecdotally and personally observed by the author that even travelling to the most popular tourism destinations in Pakistan, it is impossible to find any local souvenirs handcrafted in Pakistan, such as spoons, cups or fridge magnets, even local road maps, as opposed to cheap trinkets produced outside of the country. It is important to plan heritage tourism within the goal of providing products and services that would be kept by tourists forever and hence increase the memorability of the experience.

The satisfaction of tourists has been defined and identified for experiential heritage tourism in Pakistan. Over reliance on general descriptors of satisfaction such as effective bookings, punctuality, good pricing, product knowledge, and post travel experience will never make Pakistan a competitive tourism destination (Haq \& Medhekar, 2019). 


\section{NBR \\ 1,1}

Page 08

Table 2.

Design

Thinking steps

accomplished in

this research
Based on the secondary data, it is suggested that at least proper communication and knowledge of a heritage site must be given priority for organizers of heritage tourism in Pakistan. The final element of authenticity has been discussed as the most competitively differentiating element in today's heritage tourism. Seraphim and Haq (2019) have illustrated in their qualitative study that authenticity, or there lack of, is the key element for heritage tourism in the UAE. In Pakistan, there may not be a shortage of authenticity in heritage tourism, yet the organizers need to use it as a strength for presentations.

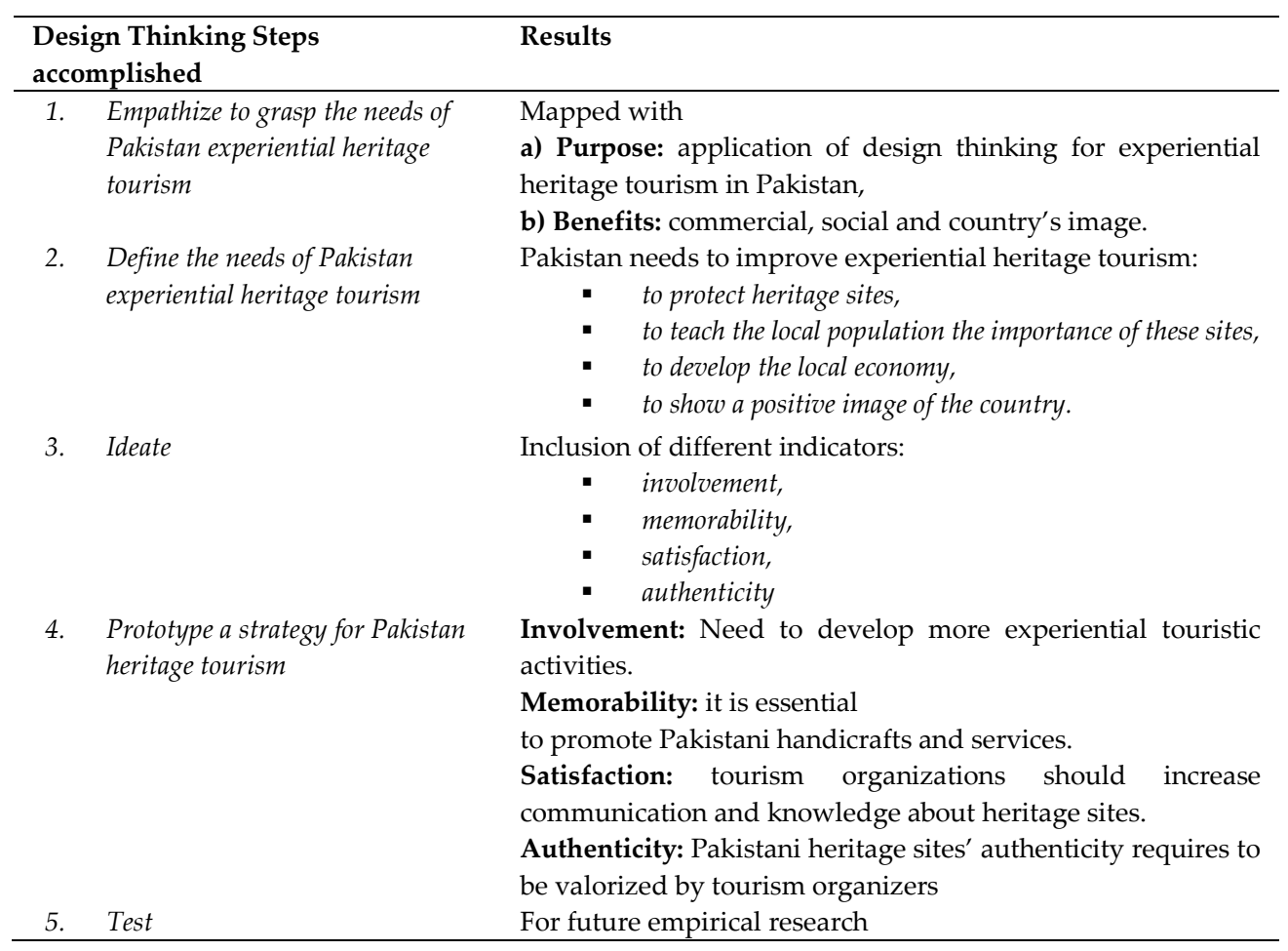

\subsection{Conclusions and Future Research Direction}

This conceptual study has raised the issue of highlighting the potential of experiential heritage tourism in Pakistan. Various elements hindering the growth have also been identified in this study. In order to enhance the experiential heritage tourism, this study has mapped it with the innovative design thinking process. The methodological contribution of applying innovative design thinking process for secondary data analysis is that it enabled the data to make sense. This method provides an organized process that facilitates understanding the experience of different stakeholders in the context of heritage experiential tourism. Then, develop strategies and finally refine one final solution based on this understanding. 
NBR

1,1

Page 09

The elements of involvement, memorability, satisfaction, and authenticity have been explained with respect to innovation in heritage tourism. The study also concludes that regular innovations are very generic and niche innovations are outdated for heritage tourism; perhaps two decades earlier niche innovations were more applicable for heritage tourism. In analyzing secondary data about experiential heritage tourism in general, four essential indicators emerge: involvement, memorability, satisfaction, and authenticity. These indicators are used to understand what is required to improve experiential heritage tourism in Pakistan. The strategy to strengthen experiential heritage tourism in Pakistan is based on these four intrinsically linked indicators: to reach the tourists' satisfaction, experiential touristic activities involving more tourists are needed, and increasing memorability of the tourists' experience. Authenticity promotion also leads to more memorability and a higher tourist 'satisfaction.

The limitation of the study is the originality of the research based on concepts borrowed from external sources rather than any credible Pakistani tourism data. A future empirical study is suggested to be based on the four elements of experiential heritage tourism, there is a gap to be filled about how to use them. For example, how the memorability could be improved. This can be done only by investigating various stakeholders including tourists, tourism providers and managers, food and accommodation managers, and transport managers. A quantitative study with a positivist mindset could be used to understand the specific tastes and preferences of tourists regarding the given elements. A qualitative study with the paradigm of realism is proposed to identify issues and ideas from the tourism operators based on these elements of heritage tourism.

The authors declare no conflict of interest.

\section{References}

Andrades, L., and Dimanche, F. (2014), "Co-Creation of experience Value: A tourist Behavior Approach", in Prebensen N, Chen, J., and Uysal, M. (Eds.), Creating Experience Value in Tourism, Cabi, London, pp. 95-112.

Balmer, J. M. and Chen, W., (2016), "Corporate heritage tourism brand attractiveness and national identity", Journal of Product \& Brand Management, 25(3), pp. 223-238. Baloch, Q. B., (2007), "Managing tourism in Pakistan: A case study of Chitral valley", Journal of Managerial Sciences, 2(2), pp. 169-190.

Cary, S.H., (2004), "The tourist moment", Annals of Tourism Research, 31(1), pp. 6177.

Chhabra, D., Healy, R., and Sills, E., (2003), "Staged authenticity and heritage tourism", Annals of tourism research, 30(3), pp. 702-719. 
NBR

1,1

Page 10

Denzin, N. K., (2012), “Triangulation 2.0”, Journal of mixed methods research, 6(2), pp. 80-88.

D.school. (2010), "An Introduction to Design Thinking Process Guide". Hasso Platner Institute of Design at Stanford, available at: https://dschoolold.stanford.edu/sandbox/groups/designresources/wiki/36873/attachments/74b3d/ ModeGuideBOOTCAMP2010L.pdf (accessed 26 August 2019).

Hamilton-Smith, E., (1987), "Four kinds of tourism", Annals of Tourism Research, 14(3), pp. 332-344.

Haq, F. and Jackson, J., (2009), "Spiritual journey to Hajj: Australian and Pakistani experience and expectations", Journal of Management, Spirituality \& Religion, 6(2), pp. 141-156.

Haq, F., and Medhekar, A. (2019), "Challenges for innovative transformation in heritage tourism development in India and Pakistan", in Srivastava, S. (Ed.), Conservation and Promotion of Heritage Tourism, IGI Global Publishing, Pennsylvania: USA, pp. 127-154.

Havitz, M.E. and Dimanche, F., (1997), “Leisure involvement revisited: Conceptual conundrums and measurement advances", Journal of Leisure Research, 29(3), pp. 245-278.

Hjalager, A.M., (2010), "A review of innovation research in tourism", Tourism Management, 31(1), pp. 1-12.

ICOMOS. (2002), "A Cultural Heritage Manifesto", available at: http://www.icomosuk.org/uploads/sidebar/PDF/A\%20Cultural\%20Heritage\%20M anifesto.pdf (accessed 5 June 2019).

IDEOU. (2018), "What is Design Thinking?", Available at https://www.ideou.com/blogs/inspiration/what-is-design-thinking. (Accessed 4 October 2018).

Kelley, T., and Kelley D. (2013). "A Solution for Poor Mothers, When Expensive Hospital Incubators Won't Do", Slate, available at: https://slate.com/humaninterest/2013/11/embrace-infant-warmer-creative-confidence-by-tom-and-david-

kelley.html (accessed 10 September 2019).

Liedtka, J., Salzman, R., and Azer, D. (2017), Design Thinking for the Greater Good: Innovation in the Social Sector, Columbia Business School Publishing, Columbia University.

Laurent, G. and Kapferer, J.N., (1985), "Measuring consumer involvement profiles", Journal of Marketing Research, 22 (1), pp. 41-53.

Meyer, C., and Schwager, A., (2007), "Understanding Customer Experience", Harvard Business Review, 85(2), pp. 116-126.

Otto, J. and Ritchie, J.R.B., (1996), "The service experience in tourism", Tourism Management, 17(3), pp. 165-174.

Pakistan Bureau of Statistics. (2017), "Pakistan Statistical Year Book 2017", available at: http://www.pbs.gov.pk/content/pakistan-statistical-year-book-2017 (accessed 20 May, 2019). 
NBR

1,1

Papadimitriou, D., Kaplanidou, K. and Apostolopoulou, A., (2018), “Destination image components and word-of-mouth intentions in urban tourism: A multigroup approach", Journal of Hospitality \& Tourism Research, 42(4), 503-527.

Redfoot, D.L., (1984), "Touristic authenticity, touristic angst, and modern reality", Qualitative Sociology, 7, pp. 291-309.

Seraphim, J., and Haq, F. (2019), "Challenges for Promotion of Heritage Tourism: Case Study of the UAE", in Srivastava, S. (Ed.), Conservation and Promotion of Heritage Tourism, IGI Global Publishing, Penn, USA, pp. 35-56.

The Express Tribune. (2019). "Pakistan about to become tourism's next big thing", available at: https://tribune.com.pk/story/1946713/1-pakistan-become-tourismsnext-big-thing/ (accessed on on 8 September, 2019).

UNESCO. (2019), "Properties Inscribed On The World Heritage: Pakistan", World Heritage Centre (WHC), available at: https://whc.unesco.org/en/statesparties/pk (accessed on 11 June, 2019).

UNWTO. (2018), “Tourism Highlights: 2018 Edition”, available at: https://www.eunwtoorg/doi/book/10.18111/9789284419876 (accessed June 17 2019)

UNWTO. (2019), "International Tourist Arrivals Reach 1.4 billion Two Years Ahead of Forecast", available at https://www2.unwto.org/press-release/2019-0121/international-tourist-arrivals-reach-14-billion-two-years-ahead-forecasts (accessed 8 September 2019).

Weiermair, K., (2006), "Product improvement or innovation: What is the key to success in tourism?", in OECD. (Ed), Innovation and Growth in Tourism, Paris, pp. 53-67.

\section{About Author}

\section{Joanna Seraphim}

Dr. Joanna Seraphim is the Head of Incubation at Amity University, Dubai, UAE. Previously she has worked at Canadian University of Dubai, UAE. Her research interests include design thinking, entrepreneurship, startups, tourism, and marketing.

\section{Farooq Haq}

Dr. Haq holds a PhD in Marketing from Charles Darwin University, Darwin and an MBA in Marketing from Central Queensland University, Rockhampton, Australia. Dr Haq is considered as a pioneer of research in Marketing Spiritual Tourism and a recognized expert of Islamic Marketing. Since 2016, he has been a member of the Editorial Board for the Journal of Islamic Marketing, Emerald, Scopus listed and the Journal of Management and Research.

The Corresponding Author Dr Farooq Haq can be contacted at: farooq@cud.ac.ae 